\title{
How common is hypothyroidism after external radiotherapy to neck in head and neck cancer patients?
}

\author{
Nirmala Srikantia, \\ Karthik S. Rishi', \\ M. G. Janaki, \\ Ramesh S. Bilimagga, \\ Arul Ponni, \\ A. G. Rajeev, \\ Kirthi Kaushik, \\ Mala Dharmalingam ${ }^{1}$
}

Departments of Radiotherapy and ${ }^{1}$ Endocrinology, MS Ramaiah Medical College, Bengaluru, and ${ }^{2}$ Manipal Hospital, Bengaluru, Karnataka, India

\section{Address for correspondence: \\ Prof. Nirmala Srikantia, \\ Department of Radiotherapy, \\ M S Ramaiah Medical College, \\ Bangalore - 560 054, \\ Karnataka, India. \\ E-mail: drknmrao@gmail.com}

\begin{abstract}
A B S T R A C T
Purpose: To identify the occurrence of clinical and subclinical hypothyroidism among head and neck cancer patients receiving radiation to the neck and to justify routine performing of thyroid function tests during follow-up. Materials and Methods: This is a prospective nonrandomized study of 45 patients of head and neck cancer, receiving radiotherapy (RT). Thyroid stimulating hormone and T4 estimations were done at baseline and at 4 months and 9 months following RT. Results: Of the 45 patients, 37(82.2 \%) were males and eight $(17.8 \%)$ were females. All patients received radiation to the neck to a dose of $>40 G y$. $35.6 \%$ received concurrent chemotherapy. Two patients underwent prior neck dissection. Fourteen patients $(31.1 \%)$ were found to have clinical hypothyroidism ( $P$ value of 0.01$)$. Five $(11.1 \%)$ patients were found to have subclinical hypothyroidism with a total 19 of $45(42.2 \%)$ patients developing radiation-induced hypothyroidism. Nine of 14 patients with clinical hypothyroidism were in the age group of 51 to 60 years $(P=0.0522)$. Five of 16 patients who received chemoradiation and nine of 29 who received RT alone developed clinical hypothyroidism. Above 40 Gy radiation dose was not a relevant risk factor for hypothyroidism. Conclusion: Hypothyroidism (clinical or subclinical) is an under-recognized morbidity of external radiation to the neck which is seen following a minimum dose of $40 \mathrm{~Gy}$ to neck. Recognizing hypothyroidism (clinical or subclinical) early and treating it prevents associated complications. Hence, thyroid function tests should be made routine during follow-up.
\end{abstract}

Key words: Head and neck cancer, hypothyroidism, radiotherapy, subclinical hypothyroidism

\section{INTRODUCTION}

The thyroid gland is the largest pure endocrine gland in the human body situated in the anterior neck in front of the trachea. The thyroid gland secretes two main thyroid hormones, triiodothyronine (T3) and thyroxine (T4), which are crucial in normal growth and development.

Head and neck cancers rank fifth among all malignancies worldwide and the commonest malignancy among Indian males. ${ }^{[1]}$ This is probably due to the increased use of tobacco in various forms.

\begin{tabular}{|l|l|}
\hline \multicolumn{2}{|c|}{ Access this article online } \\
\hline Quick Response Code: & Website: \\
\hline & www.jmpo.org \\
\hline
\end{tabular}

The treatment of head and neck cancers include surgery, radiotherapy (RT), chemotherapy, and a combination of these. RT is the only curative treatment, besides surgery, in the management of patients with head and neck cancer. Majority of head and neck tumors are locoregionally advanced at the time of diagnosis. Hence, RT portals, apart from including the primary site of the tumor, will invariably cover the whole neck, thereby including the thyroid gland in the radiation field leading to its dysfunction.

Impact of RT on thyroid function was first reported in 1929. ${ }^{[2]}$ The radiation-induced thyroid injury includes vascular damage, parenchymal cell damage, and autoimmune reactions. Total RT dose, irradiated volume of thyroid gland, and the extent of prior thyroid resection are the important factors associated with the risk of hypothyroidism.

Despite a relatively high number of both animal and human studies, clear-cut data on the incidence, type, pathophysiology, and severity of radiation induced thyroid dysfunction are scarce and inconsistent. Reports on thyroid 
disorders after RT are mostly retrospective, lack pre $v$ s. post irradiation evaluation, include heterogeneous and small patient populations, and are based on short follow-up. Only a few prospective analyses are available. ${ }^{[3,4]}$

The most common clinical late effect of thyroid gland irradiation in patients exposed to therapeutic doses to the neck is hypothyroidism. This effect may be clinically overt (clinical hypothyroidism) characterized by low free T4 and high thyroid stimulating hormone (TSH), or subclinical (biochemical or compensated hypothyroidism) with normal free T4 and high TSH. In the majority of cases, subclinical hypothyroidism evolves to clinical hypothyroidism. ${ }^{[5]}$ Progression to clinical hypothyroidism occurs at a rate of about 5 to $20 \%$ per year.

Subclinical thyroid dysfunction, which can be diagnosed by thyroid function, is more frequent but is often missed because routine testing of thyroid hormones is not done during follow-up. Consequence of subclinical hypothyroidism are much less well established, most of the literature refers to adverse consequences such as cardiac dysfunction, adverse cardiac end points, including atherosclerotic disease and cardiovascular mortality, elevation in total and low density lipoprotein, systemic or neuropsychiatric symptoms, and progression to clinical hypothyroidism. ${ }^{[6-9]} \mathrm{T} 4$ replacement improves cardiac function in subjects with subclinical hypothyroidism. The clinical manifestations of clinical hypothyroidism include slowed mentation, depression, chronic fatigue, skin dryness, pleural and pericardial effusions, decreased gastrointestinal motility, weight gain, cold intolerance, congestive heart failure, and acceleration of atherosclerosis. ${ }^{[10]}$

Greater magnitude and duration of TSH elevation increase the probability of progression to clinical hypothyroidism and therefore increase the potential benefit of treatment of subclinical hypothyroidism. Recognizing subclinical hypothyroidism at an early stage can hence prevent clinical hypothyroidism and its attendant morbidity. ${ }^{[10]}$

RT-induced hypothyroidism has remained under estimated and under reported, because routine assessment of thyroid function is not done during follow-up, resulting in failure to detect and treat a reversible cause of morbidity for a significant proportion of surviving patients.

Hence, the purpose of this study is to identify the magnitude of hypothyroidism following RT to the neck, to assess the mean time period for the development of hypothyroidism, usefulness of TSH and total T4 in identifying and treating patients with subclinical thyroid dysfunction, and to stress upon the necessity of including thyroid function tests as part of follow-up.

\section{MATERIALS AND METHODS}

The study was conducted in patients with histopathologically proven head and neck cancer receiving external beam RT to the whole neck on Telecobalt between September 2005 and August 2007.

The patients included were of any age, both the sexes with normal thyroid function receiving External Beam Radiotherapy to the neck with thyroid gland in the field of RT to dose of $>40$ Gy and those excluded were patients with history of previous thyroid surgery, pre-existing thyroid disease, recurrent disease, prior RT to neck, or those receiving $<40 \mathrm{~Gy}$ to the neck. A total of 45 patients were included in the study.

A single baseline TSH and Total T4 test was done before the start of Radiotherapy for all patients. Informed consent was obtained before the start of the treatment.

Patients were treated with Cobalt 60 teletherapy unit with conventional fractionation of 1.8 to $2 \mathrm{~Gy} / \mathrm{Fr} /$ day for 5 days a week. The treatment portals included the primary tumor with margin and the whole neck. Primary and the upper neck were treated with two lateral portals and lower neck was treated with a separate anterior portal up to $50 \mathrm{~Gy}$. In nasopharyngeal carcinomas with anterior extension, an anterior portal was added to the primary. After $4000-4500 \mathrm{cGy}$, the field was reduced to spare the spinal cord. Subclinical disease was excluded at $5000 \mathrm{cGy}$ and only the primary and the gross nodes were treated up to 6600 to $7000 \mathrm{cGy}$. The treatment intent was either radical or postoperative adjuvant. Few patients received concurrent chemoradiation with weekly Cisplatin at $40 \mathrm{mg} / \mathrm{m}^{2}$ of body surface area.

Blood samples were obtained at fourth month and ninth month following RT for TSH and total T4 estimation. $5 \mathrm{ml}$ blood was collected in a vacutainer and the serum and plasma were separated by centrifugation. TSH estimation was done using immunoradiometric assay and total T4 estimation was done using the Radioimmunoassay kits. Stratec automated analyzer was used to calculate the TSH and $\mathrm{T} 4$ values. The normal values used for the study were TSH $-0.5-5.1 \mathrm{mIU} / 1$ and T4 - $4.6-12.4 \mu \mathrm{g} / \mathrm{dl}$.

\section{Statistical methods}

Z-test for binomial single proportion has been used to find the significance of occurrence of hypothyroidism according to age, sex, chemotherapy, surgical treatment, and diagnosis. Mean test has been used to find the correlation with radiation dose and hypothyroidism occurrence. Paired proportion test - online statistical software developed by University of Baltimore, USA - has been used to find the significance of study parameters between admission and discharge. 


\section{Software}

The statistical software namely SPSS 11.0, Stata 8.0, Systat 11.0, Medcalc 9.0.1, and Effect Size calculator were used for the analysis of the data and Microsoft word and Excel have been used to generate graphs, tables, etc.

\section{RESULTS}

\section{Patient characteristics}

In this prospective, nonrandomized clinical study of 45 patients, $37(82.2 \%)$ were males and eight $(17.8 \%)$ were females and majority were in the age group of 40 to 70 years [Table 1]. Primary in majority of the patients was carcinoma hypopharynx (35.6\%) [Table 2]. 35.6\% received concurrent chemotherapy and $64.4 \%$ received RT alone. Only two patients underwent prior surgery in the form of neck dissection before RT.

\section{Radiation-induced hypothyroidism}

The occurrence of clinical and subclinical hypothyroidism is studied over a follow-up period of 9 months in this prospective nonrandomized trial.

Fourteen patients $(31.1 \%)$ were found to have clinical hypothyroidism. This was strongly significant with a $P$ value of 0.00027 . Five patients $(11.1 \%)$ were found to have subclinical hypothyroidism. In total, 19 of $45(42.2 \%)$ patients had radiation-induced hypothyroidism [Table 3].

Among the patients who developed hypothyroidism, 9 of 14 were in the age group of 51 to 60 years $(P=0.0522)$, which had a suggestive significance [Table 4]. Among males, 10 of 37 and among females, four of eight developed clinical hypothyroidism [Table 5]. Five of 16 patients who received concurrent chemoradiotherapy and nine of 29 who received RT alone developed clinical hypothyroidism [Table 6]. Only two patients underwent surgery prior to RT and of them, one developed clinical hypothyroidism. Above 40 Gy radiation dose did not have any significant contribution for development of hypothyroidism [Table 7]. All the patients who developed hypothyroidism, either clinical or subclinical, were seen by the Endocrinologist and put on thyroid supplementation.

\section{DISCUSSION}

Impact of RT on thyroid function was first reported in 1929. ${ }^{[2]}$ A number of studies done as early as in 1960s have reported the development of hypothyroidism after RT for head and neck malignancies. ${ }^{[1,12]}$ Documented incidences of primary hypothyroidism after RT have varied from 3 to $47 \%$. An incidence of 20 to $30 \%$ has been reported by most investigators. ${ }^{[13]}$
In general, it seems that external irradiation of the normal thyroid may cause dysfunction of the gland within months

\begin{tabular}{lc}
\hline Table 1: Patient characteristics \\
\hline \\
Sex & $\boldsymbol{N}(\%)$ \\
Male & \\
Female & $37(82.2)$ \\
Total & $8(17.8)$ \\
Age & 45 \\
$34-40$ & \\
$41-50$ & $1(2.2)$ \\
$51-60$ & $12(26.7)$ \\
$61-70$ & $17(37.8)$ \\
$>70$ & $11(24.4)$ \\
Total & $4(8.9)$ \\
\hline
\end{tabular}

\begin{tabular}{lc}
\hline Table 2: Primary site & \\
\hline Hypopharyngeal Ca & $16(35.6)$ \\
Oropharyngeal Ca & $13(28.9)$ \\
Ant 2/3 tongue Ca & $4(8.9)$ \\
Supraglottic Ca & $8(17.8)$ \\
Sec. neck from unknown primary & $2(4.4)$ \\
Nasopharyngeal Ca & $2(4.4)$ \\
\hline
\end{tabular}

Ca-Carcinoma

\begin{tabular}{|c|c|c|c|}
\hline Outcome $(n=45)$ & Before RT & 9 months post-RT & $P$ value \\
\hline Normal & $45(100)$ & $26(57.8)$ & 0.0188 \\
\hline Subclinical & o & $5(11)$ & 0.1267 \\
\hline Clinical & 0 & $14(31.1)$ & 0.00027 \\
\hline
\end{tabular}

RT - Radiotherapy; Paired proportion test

\begin{tabular}{|c|c|c|c|}
\hline $\begin{array}{l}\text { Age in } \\
\text { years }\end{array}$ & $\begin{array}{l}\text { Number of } \\
\text { patients }\end{array}$ & $\begin{array}{l}\text { Patients with hypothyroidism } \\
\text { number - \% }\end{array}$ & $P$ value \\
\hline $34-40$ & 1 & $0-0$ & 0.5027 \\
\hline $41-50$ & 12 & $2-16.7$ & 0.2812 \\
\hline $51-60$ & 17 & $9-52.9$ & 0.0522 \\
\hline $61-70$ & 11 & $2-18.2$ & 0.3553 \\
\hline$>70$ & 4 & $1-25.0$ & 0.7921 \\
\hline Total & 45 & $14-31.1$ & 0.00027 \\
\hline
\end{tabular}

\begin{tabular}{|c|c|c|c|c|}
\hline \multicolumn{5}{|c|}{$\begin{array}{l}\text { Table 5: Occurrence of hypothyroidism } \\
\text { according to gender }\end{array}$} \\
\hline Gender & $\begin{array}{l}\text { Number of } \\
\text { patients }\end{array}$ & $\begin{array}{l}\text { Number of patients with } \\
\text { clinical hypothyroidism }\end{array}$ & $\%$ & $P$ value \\
\hline Male & 37 & 10 & 27.00 & 0.5992 \\
\hline Female & 8 & 4 & 50.0 & 0.2482 \\
\hline Total & 45 & 14 & 31.1 & \\
\hline
\end{tabular}




\begin{tabular}{lcccc}
\hline \multicolumn{5}{l}{ Table 6: Occurrence of hypothyroidism } \\
according to chemotherapy \\
\hline Chemotherapy & $\begin{array}{c}\text { No. of } \\
\text { patients }\end{array}$ & $\begin{array}{c}\text { No. of patients with } \\
\text { hypothyroidism }\end{array}$ & $\%$ & P value \\
Received & 16 & 5 & 31.3 & 0.9862 \\
Not received & 29 & 9 & 31.03 & 0.3207 \\
Total & 45 & 31 & 31.1 & \\
\hline Z test & & &
\end{tabular}

\begin{tabular}{|c|c|c|c|}
\hline \multicolumn{4}{|c|}{$\begin{array}{l}\text { Table 7: Occurrence of hypothyroidism } \\
\text { according to radiation dose above } 40 \mathrm{~Gy}\end{array}$} \\
\hline Clinical status & Normal & Subclinical & Clinical \\
\hline Mean (Gy) & 57.27 & 62.8 & 63.71 \\
\hline $95 \% \mathrm{Cl}$ for mean & 52.28 to 62.25 & 53.74 to 71.85 & 58.55 to 68.87 \\
\hline \multicolumn{4}{|l|}{ RT dose (Gy) } \\
\hline Minimum & 40 & 50 & 40 \\
\hline Maximum & 70 & 68 & 70 \\
\hline Range & 30 & 18 & 30 \\
\hline
\end{tabular}

RT - Radiotherapy; ANOVA mean test

to years following treatment. The study with the longest follow-up of patients was that presented by Einhorn and Wikholm. With 10-year follow-up in 41 patients of carcinoma of the larynx and hypopharynx treated with RT, the incidence of established hypothyroidism was $7.3 \% .{ }^{[14]}$

Glatstein et al. have observed a high incidence of thyroid dysfunction in patients treated with RT for Hodgkin's disease and malignant lymphoma. ${ }^{[15]}$ This is true both for the incidence of "compensated hypothyroidism" (normal level of T4 and increased levels of TSH) and for the incidence of clinical hypothyroidism (decreased level of T4 and elevated TSH $(P<0.05)$.

Alterio et al. mentioned that among different radiation-induced late effects, thyroid disorders are underestimated. Among thyroid disorders, primary hypothyroidism seems to be the most frequent late effect with an incidence of 20 to $30 \%{ }^{[16]}$

The minimal thyroid tolerance dose defined as TD5/5 (the dose of radiation that could cause no more than $5 \%$ severe complication rates within 5 years after treatment) is considered $20 \mathrm{~Gy}$ when all or part of the gland is irradiated with conventional fractionation. ${ }^{[17]}$

Emami et al. reported different tolerance values of $8 / 5$, $13 / 5$, and $35 / 5$ (incidence of clinical hypothyroidism in $8 \%, 13 \%$, and $35 \%$ of patients at 5 years) at the level of 45,60 , and 70 Gy, respectively. ${ }^{[18]}$

In our study, the age group of patients varied from 34 to 85 years with a mean of 60 years. Mean age of men was higher ( 58.78 years) as compared with women ( 52.13 years).
Thirty-seven $(82.2 \%)$ were males and eight $(17.8 \%)$ were females. These patient characteristics were similar to other studies published..$^{[1,20]}$ Majority of the cancers were seen to arise from the hypopharynx $(35.6 \%)$. The primary site varied in literature. Aich had a higher percentage of cancers arising from the larynx (49\%). ${ }^{[2]}$ The primary site of the tumor was not a significant factor as all the patients received whole-neck irradiation and hence uniformity in the volume of thyroid irradiated.

All patients in the study received a dose of $>40 \mathrm{~Gy}$ in conventional fractionation to the whole neck. $64.4 \%$ received more than $60 \mathrm{~Gy}$ to neck with a mean dose of $57.54 \mathrm{~Gy}$. This is again in concordance with the literature where, except for studies on children treated for Hodgkin's, the minimum dose was $40 \mathrm{~Gy}$ to the neck and it went up to $70 \mathrm{~Gy}$ in patients with a radical intent. ${ }^{[19-22]}$

$16(35.6 \%)$ patients received chemotherapy either concurrent (15 patients) or neoadjuvant (one patient) and $29(64.4 \%)$ patients received RT alone. The use of chemotherapy in head and neck cancers varies from center to center. Turner $e t$ al. had a very high number of patients receiving chemotherapy (77\%). ${ }^{[22]}$ Mercado et al. had 50\% of the patients receiving chemotherapy. ${ }^{[23]}$ These studies had a higher percentage of patients with locally advanced disease or were randomized to compare the effect of chemotherapy on tumor response as well as incidence of hypothyroidism. In our study, though many of the patients were locally advanced, chemotherapy was deferred in view of poor performance status or unaffordability.

In our study, the minimum follow-up period was 9 months post-RT, which is lower than the majority of studies. Tell et al. followed up patients up to 3 years; Turner et al. had a mean follow-up of 21 months. ${ }^{[19,22]}$ In our study, 14 of $45(31.1 \%)$ patients developed clinical hypothyroidism at 9-month follow-up, which is statistically strongly significant $(P<0.00027)$. In the study, we also evaluated the thyroid status at 4-month post-RT and we noticed that six (14\%) patients had developed clinical hypothyroidism during this time.

The earliest follow-up was done by Aich who evaluated the thyroid status at 6 -week post-RT. They noticed a $4.2 \%$ incidence of clinical hypothyroidism at 12 months and not earlier. ${ }^{[20]}$

The incidence rate is high in our study when compared with other studies. The incidence in studies varies from 3 to $40 \%$. Colevas et al. noted that $50 \%$ of the patients who developed hypothyroidism did so in the first year. ${ }^{[24]}$

This is one of the few studies which had a high incidence 
at first year. Most studies however have a lower rate even after the end of the second year. Tell et al. found that the Kaplan-Meier predictive risk for hypothyroidism after 5- and 10-year post-irradiation was only $20 \%$ and $27 \%$, respectively. ${ }^{[25]}$ Aich had an incidence of $16.6 \%$ at the end of 2-year follow-up. ${ }^{[20]}$

In our study, $52.9 \%$ of the patients developing clinical hypothyroidism were between the age groups of 51 to 60 years [Table 7]. This had statistically suggestive significance $(P=0.0522)$. Colevas et al. stated that there was an increased incidence in patients with age more than 60 years. ${ }^{[24]}$ Hancock et al. stated that the relative risk of primary hypothyroidism decreased by a factor of 0.99 with each additional year of age. ${ }^{[2]}$ In our study, the occurrence was definitely higher in the elder age group as compared with the younger; however, the mean patient age groups analyzed were also in the range of 52 years.

There was a higher occurrence among female patients (50\%, F: $\mathrm{M}=1.5: 1)$, but this was not statistically significant as the number was very less. Posner et al. stated that female sex has been associated with $20 \%$ increased hypothyroidism and Hancock et al. observed an increased relative risk of 1.6: 1 in females. ${ }^{[26,27]}$

When we analyzed the occurrence of hypothyroidism, both clinical and subclinical against dose, it was found to be nonsignificant. That means to say that above $40 \mathrm{~Gy}$ radiation dose is not a significant factor contributing to hypothyroidism. This is supported by Mercado et al. In their study of 155 patients, they observed that the likelihood of developing hypothyroidism could not be predicted according RT dosage to the primary site or to the neck. Only race was a predictive factor in their study ${ }^{[23]}$ In a study by Koc and Capoglu, univariate analysis of various factors failed to identify RT dose as a relevant risk factor for hypothyroidism. ${ }^{[28]}$

The occurrence of hypothyroidism was equal (31\%) both in patients who received chemotherapy and in patients who did not. This was not statistically significant. This is again supported by studies of Turner et al., Mercado et al., and Koc and Capoglu..$^{[22,23,28]}$

Aich on the contrary had a $21 \%$ incidence with the addition of chemotherapy as compared with $16.6 \%$ with RT alone. ${ }^{[20]}$

In our study, we had only two patients who had undergone surgery prior to RT and one (50\%) developed hypothyroidism. This was not statistically significant due to small number. Liening et al. divided their patients into the following three groups according to the therapy: RT alone, surgery in combination with RT, and thyroid-involving surgery and RT. They found an elevated TSH in 6\%, 28\%, and $65 \%$ patients, respectively. ${ }^{[29]}$ This indicates that with the addition of RT to thyroid surgery, the incidence increases.

In our study, we noticed five of $45(11.1 \%)$ patients developing subclinical hypothyroidism at 9 months following RT. This was not statistically significant. Wickham's survey showed that people with subclinical hypothyroidism have 38 times more risk of progression to clinical hypothyroidism. ${ }^{[4]}$ Hence, there is a definite advantage in recognizing this complication and treating it early. Aich noticed subclinical hypothyroidism as early as 6 weeks with the addition of chemotherapy and at 6 months with RT alone, with an incidence of $20.8 \%$ at 2 years. ${ }^{[20]}$ We noticed only one case at 4-month follow-up. The reported incidence in literature varies between 4 and $79 \%{ }^{[3]}$ Our incidence of $11.1 \%$ falls within this wide range, but it was not statistically significant. Cooper has stated that recognizing and treating subclinical hypothyroidism early has benefits such as prevention of clinical hypothyroidism and reduction in lipid levels, thereby reducing the cardiac complications. ${ }^{[30]}$ Tell et al. recommend lifelong TSH testing, as the incidence of clinical hypothyroidism increase with time even after long-term follow-up. ${ }^{[25]}$.

\section{CONCLUSION}

Hypothyroidism (clinical or subclinical) is an under-recognized but a significant complication of external beam irradiation to the neck.

The incidence is anywhere between 3 and $40 \%$ and it increases with time, with a peak incidence seen at 2 to 3 years. It can occur as early as 3 months following RT. It is commonly seen following a dose of $40 \mathrm{~Gy}$ to the whole neck. However, beyond 40 Gy dose is not a predictive factor. Addition of surgery, particularly thyroid surgery, has shown to increase the incidence, but addition of chemotherapy has shown no difference. Recognizing hypothyroidism (clinical or subclinical) early and treating it can prevent associated complications. Hence, thyroid function tests should be made routine during follow ups from as early as 3 months and carried out lifelong.

Use of newer technologies like three-dimensional conformal therapy and Intensity-Modulated Radiotherapy can reduce the dose to the thyroid gland when identified as organ at risk and it can be limited to $<40 \mathrm{~Gy}$, which may in future reduce the occurrence of hypothyroidism.

\section{REFERENCES}

1. Jemal A, Siegel R, Ward E, Murray T, Xu J, Smigal C, et al. Cancer statistics 2006. CA Cancer J Clin 2006;56:106-30. 
2. Grover EA, Christie AC, Merritt EA. Roentgen radiation in the treatment of hyperthyroidism: A statistical evaluation based on 305 cases. JAMA 1929;92(21): 1730 -4.

3. Nishiyama K, Tanaka E, Tarui Y, Miyauchi K, Okagawa K. A Prospective analysis of subacute thyroid dusfunction after neck irradiation. Int J Radiat Oncol Biol Phys 1996;34:439-44.

4. Sinard RJ, Tobin EJ, Mazzaferri EL, Hodgson SE, Young DC, Kunz AL, et al. Hypothyroidism after treatment for nonthyroid head and neck cancer. Arch Otolaryngol Head Neck Surg 2000;126:652-7.

5. Tunbridge WM, Evered DC, Hall R, Appleton D, Brewis $M$, Clark $\mathrm{F}$, et al. The spectrum of thyroid disease in a community: The Wickham survey. Clin Endocrinol (Oxf) 1977;7:481-93.

6. Rodondi N, Newman AB, Vittinghoff E, de Rekeneire N, Satterfield S, Harris TB, et al. Subclinincal hypothyroidism and the risk of heart failure, other cardiovascular events and death. Arch Intern Med 2005;165:2460-6.

7. Hak $A E$, Pols $H A$, Visser TJ, Drexhage HA, Hofman A, Witteman JC. Subclinical hypothyroidism is an independent risk factor for atherosclerosis and myocardial infarction in elderly women: The Rotterdam Study. Ann Intern Med 2000;132:270-8.

8. Haggerty JJ Jr, Stern RA, Mason GA, Beckwith J, Morey CE, Prange AJ Jr. Subclinical hypothyroidism: A modifiable risk factor for depression? Am J Psychiatry 1994;150:508-10.

9. Biondi B, Fazio S, Palmieri EA, Carella C, Panza N, Cittadini A, et al. Left ventricular diastolic dysfunction in patients with subclinical hypothyroidism. J Clin Endocrinol Metab 1999;84:2064-7.

10. Larsen. Williams Textbook of Endocrinology, $10^{\text {th }}$ ed. $W B$ Saunders, Philadelphia, an imprint of Elseivers; 2003.

11. Felix $H$, Dupre N, Drape $M$, Court L. Long term influence of radiotherapy for cancer of larynx on the appearance of myxedema. Lyon Med 1961;93:1043-50.

12. Markson JL, Flatman GE. Myxoedema after deep X- Ray therapy to the neck. Br Med J 1965;1:1228-30.

13. Bhandare N, Kennedy L, Malyapa RS, Morris CG, Mendenhall WM. Primary and central hypothyroidism after radiotherapy for head and neck tumours. Int $\mathrm{J}$ Radiat Oncol Biol Phys 2007;68:1131-9.

14. Einhorn J, Wikholm G. Hypothyroidism after external irradiation to the thyroid region. Radiology 1967;88:326-8.

15. Glatstein E, McHardy-Young S, Brast N, Eltringham JR, Kriss JP. Alterations in Serum Thyrotropin (TSH) and Thyroid Function following radiotherapy in patients with malignant Iymphoma. J Clin Endocrinol Metab 1971;32:833-41.

16. Alterio D, Jereczek-Fossa BA, Franchi B, D'Onofrio A, Piazzi V, Rondi E, et al. Thyroid disorders in patients treated with radiotherapy for head-and-neck cancer: A retrospective analysis of seventy-three patients. Int $\mathrm{J}$ Radiat Oncol Biol Phys 2007;67:144-50.
17. Principles and practice of radiation oncology: $4^{\text {th }}$ ed Philadelphia: Lippincott Williams and Wilkins; 2004. p. 359.

18. Emami B, Lyman J, Brown A, Coia L, Goitein M, Munzenrider JE, et al. Tolerance of normal tissue to therapeutic irradiation. Int J Radiat Oncol Biol Phys 1991;21:109-22.

19. Tell R, Sjödin H, Lundell G, Lewin F, Lewensohn R. Hypothyroidism after external radiotherapy for head and neck cancer. Int J Radiat Oncol Biol Phys 1997;39:303-8.

20. Aich RK, Deb AR, Pal S, Naha BL, Ray A. Latrogenic hypothyroidism: A consequence of external beam radiotherapy to the head neck malignancies. J Cancer Res Ther 2005; 1:142-6.

21. Bhatia S, Ramsay NK, Bantle JP, Mertens A, Robison LL. Thyroid abnormalities after therapy for Hodgkin's disease in childhood. Oncologist 1996;1:62-7.

22. Turner SL, Tiver KW, Boyages SC. Thyroid dysfunction following radiotherapy for head and neck cancer. Int J Radiat Oncol Biol Phys 1995;31:279-83.

23. Mercado G, Adelstein DJ, Saxton JP, Secic M, Larto MA, Lavertu P. Hypothyroidism: A frequent event after radiotherapy and after radiotherapy with chemotherapy for patients with head and neck carcinoma. Cancer 2001;92:2892-7.

24. Colevas AD, Read R, Thornhill J, Adak S, Tishler R, Busse P, et al. Hypothyroidism incidence after multimodality treatment for stage III and IV squamous cell carcinomas of the head and neck. Int J Radiat Oncol Biol Phys 2001;51:599-604.

25. Tell R, Lundell G, Nilsson B, Sjödin H, Lewin F, Lewensohn R. Long term incidence of hypothyroidism after radiotherapy in patients with head and neck cancer. Int J Radiat Oncol Biol Phys 2004;60:395-400.

26. Hancock SL, McDougall IR, Constine LS. Thyroid abnormalities after therapeutic external radiation. Int $\mathrm{J}$ Radiat Oncol Biol Phys 1995;31:1165-70.

27. Posner MR, Ervin TJ, Miller D, Fabian RL, Norris CM Jr, Weichselbaum RR, et al. Incidence of hypothyroidism following multimodality treatment for advanced Squamous-cell cancer of the head and neck. Laryngoscope 1984;94:451-4.

28. Koc M, Capoglu I. Thyroid dysfunction in patients treated with radiotherapy for neck. Am J Clin Oncol 2009;32:150-3.

29. Liening DA, Duncan NO, Blakeslee DB, Smith DB. Hypothyroidism following radiotherapy for head and neck cancer. Otolaryngol Head Neck Surg 1990;103:10-3.

30. Cooper DS. Subclinical Hypothyroidism. N Engl J Med 2001;345:260-5.

How to cite this article: Srikantia N, Rishi KS, Janaki MG, Bilimagga RS, Ponni A, Rajeev AG et al. How common is hypothyroidism after external radiotherapy to neck in head and neck cancer patients?. Indian J Med Paediatr Oncol 2011;32:143-8. Source of Support: Nil, Conflict of Interest: None declared.
Download

iPhone, iPad application
A free application to browse and search the journal's content is now available for iPhone/iPad. The application provides "Table of Contents" of the latest issues, which are stored on the device for future offline browsing. Internet connection is required to access the back issues and search facility. The application is Compatible with iPhone, iPod touch, and iPad and Requires iOS 3.1 or later. The application can be downloaded from http://itunes.apple.com/us/app/medknow-journals/ $\mathrm{id} 458064375$ ? $\mathrm{s}=1 \& \mathrm{mt}=8$. For suggestions and comments do write back to us. 